月 一十年四十正大

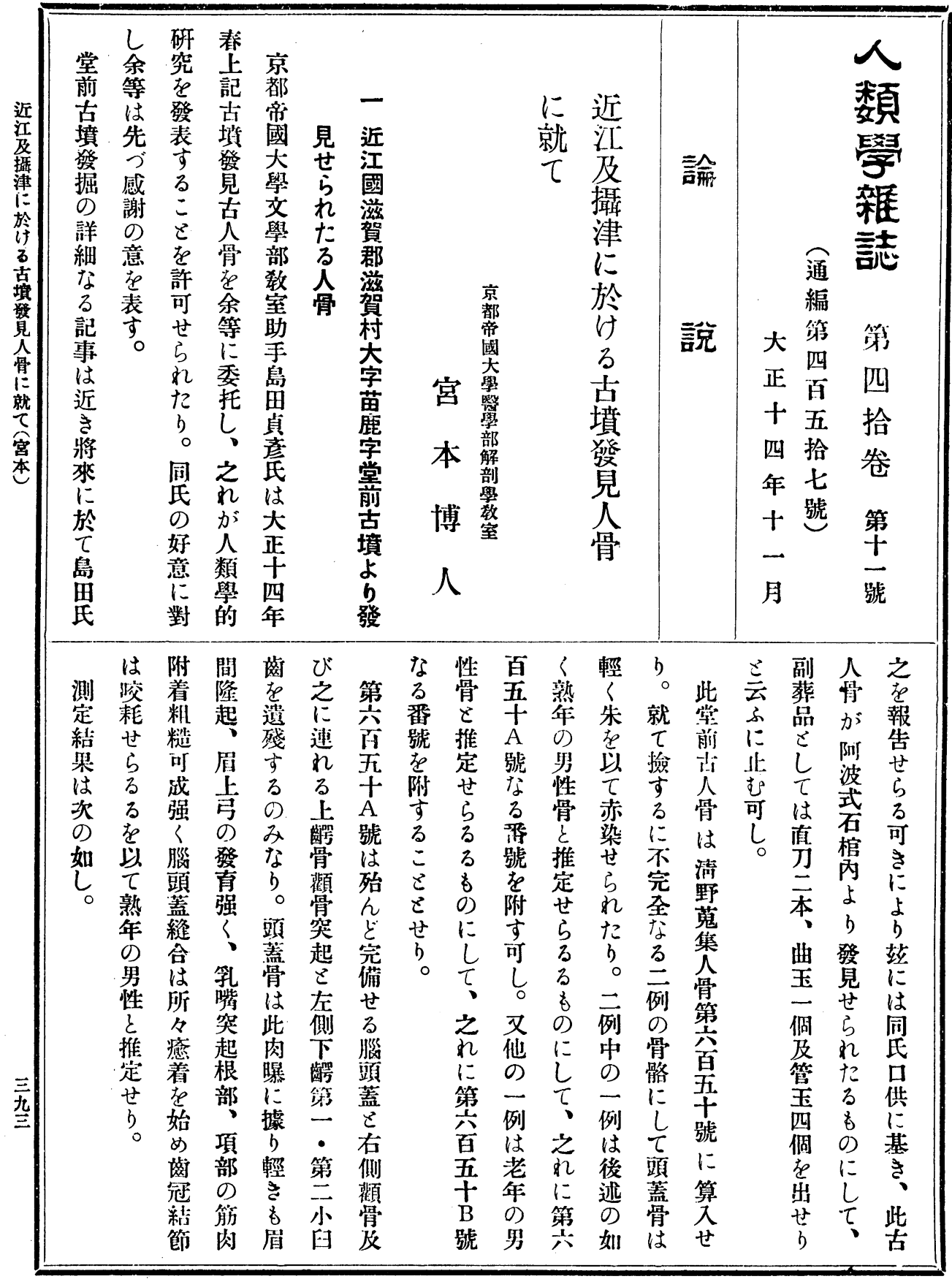


號一十第密拾四第誌雑學類人

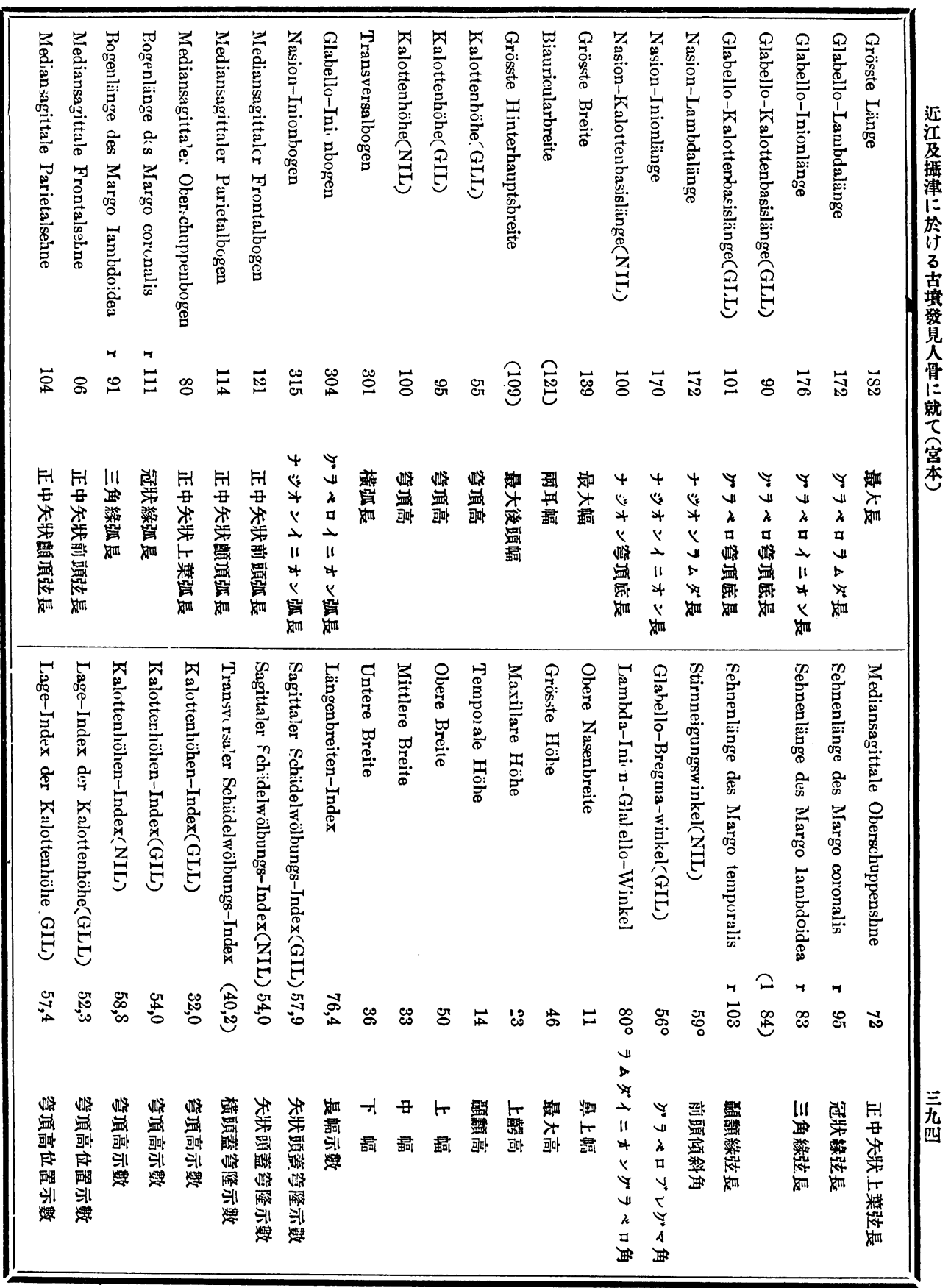


月 一 $一$ 年四十正大

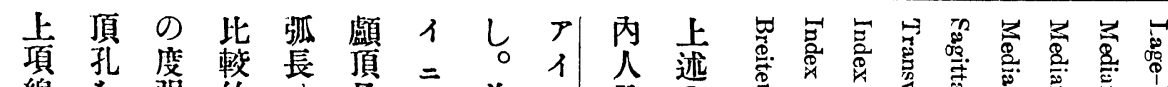

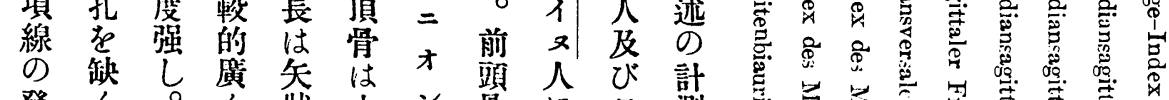
發く

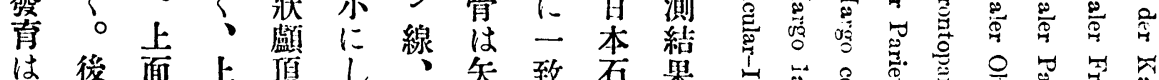

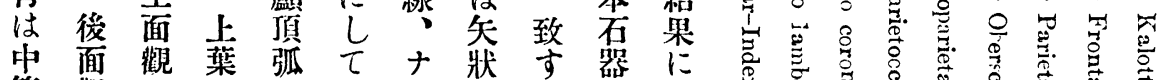
强に於白占狀才長さ代扎 な於て本り緣ン短礼人ば

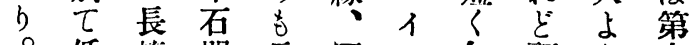

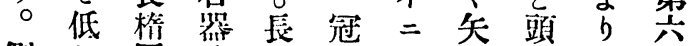

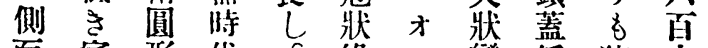

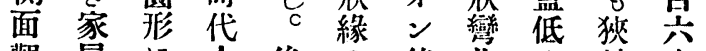
莧屋に人後の線曲々垃十

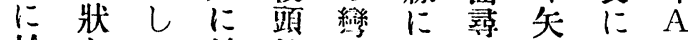

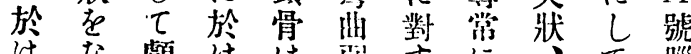

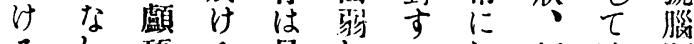
る し 頂 3 最し る $し$ 額 略 证

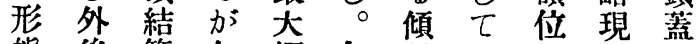
熊 後節 如幅 矢斜 グの代は は䫒弱くに狀弱ラ骂北現

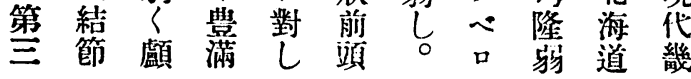

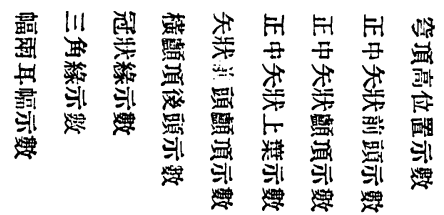

は の

尋 豊

常 淽

な 强

b

耳 䫈

阴 䁫

は 鱗

卵は

圆 小

形

に

ᄂ $\tau$

關

節 的

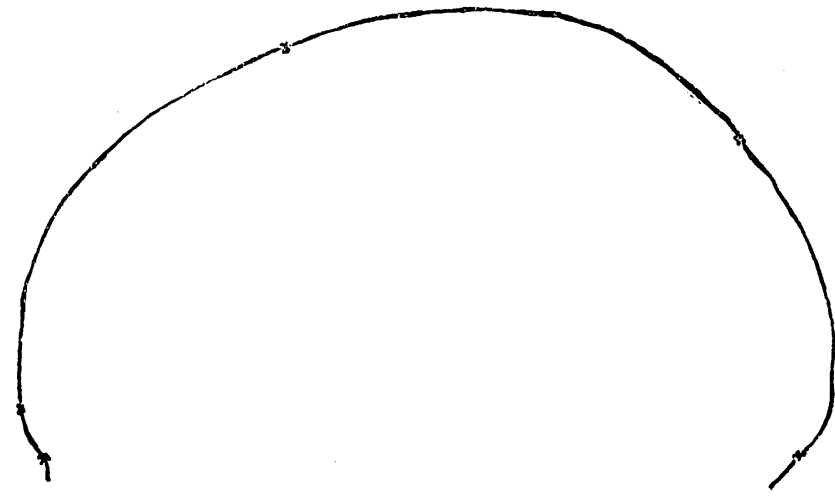




\section{號 一十第医拾四第誌雄學類人}

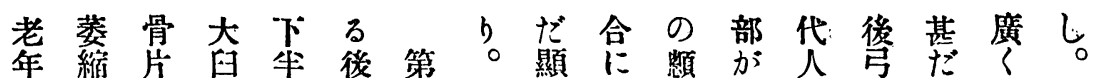

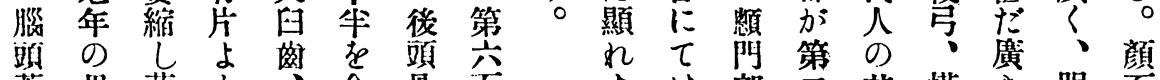

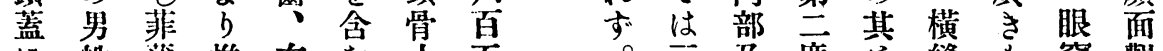

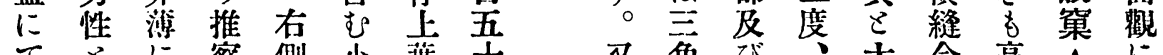

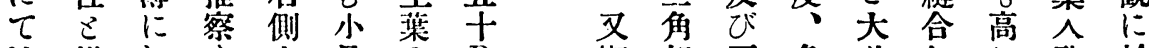

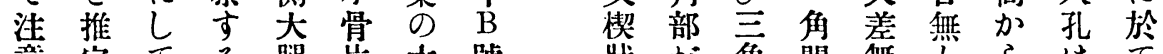

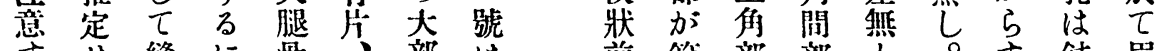
すせ縫に骨、部は 前第部部し方釛眉

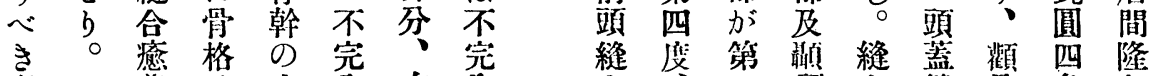
事着性上全右全 項强强坐な 侧な

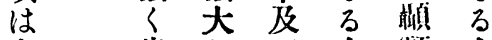

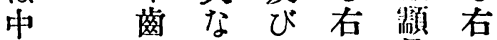
等牙り 小年骨侧 强はし 量の の 覻 の 落 か; の 下重 頂 後冠邚破踖能骨

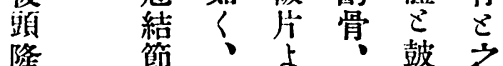
隆節り ‘䜵之

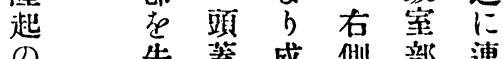
の 失羑成柋部蓮 あ る ふ。

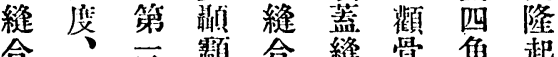

の中 度 部 癒 合絬形 䁚央度加着の節に眉

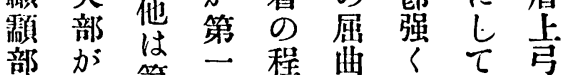

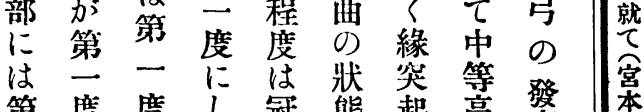
第度度し冠態起高㢹 采

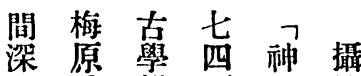

さ比雜面芹 津 一に。誌大 枋國 間 $よ$ 第 正 板 神 半风——缩 戶 內 ば四三得市 外同矮年能板 掘望八 $凵$ 山宿 b 跡 $\bigcirc$ 及 古 得 込 U 七ひ㥽 能 み構頁森 U 山 $\tau$ 造大本調古 其 は 正亲查 墳 の花二雨六に 内予 三民歷 就 部岩年の史き に缹〕つを元 石のの得地は 室地二能理梅 邑山報山第原 筑に告古一来 き徑

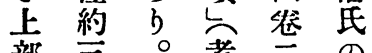

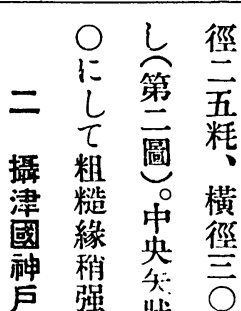

市强蔣 粍

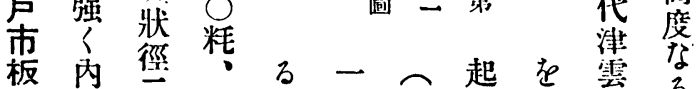

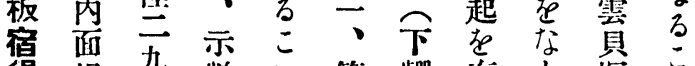

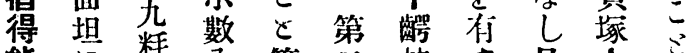
能に粍公等齐枝方县人心 山し 橫 三な 小 幅る 下に鼻

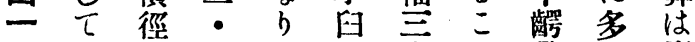

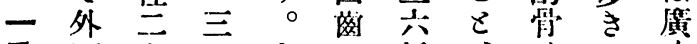
番面品に大

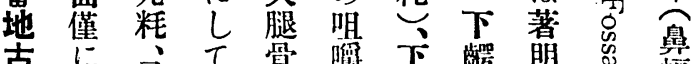

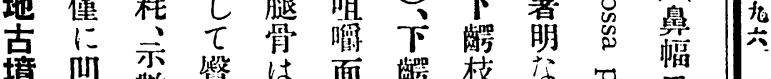

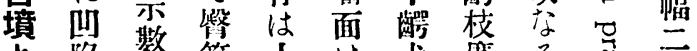
よ 陷云筋 占 發 00 粗 部 水 苳 き ○弱狀な 第を隆空其 
月 $-十$ 年四十 正大

部着起き芹片附に古の骨鏡し部䇪に

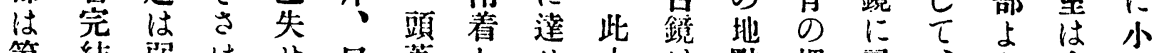

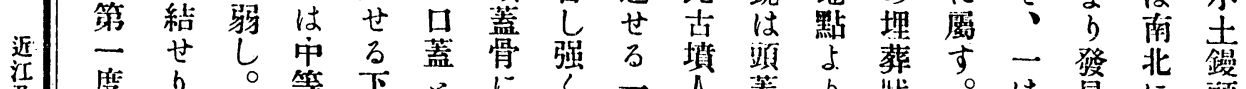

㲽度

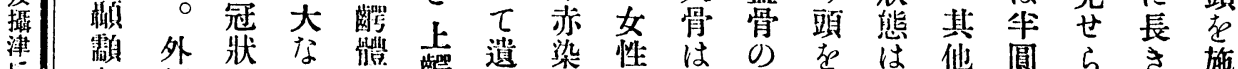

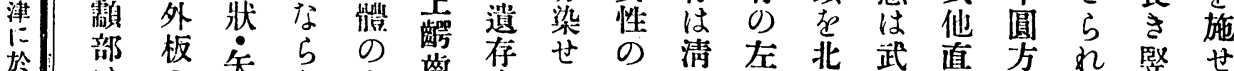

第

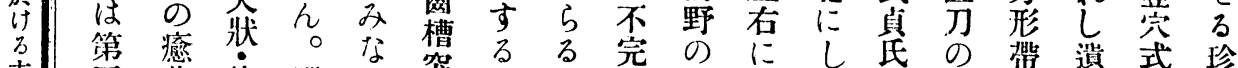

古四着 後腦 ら 乫部。完

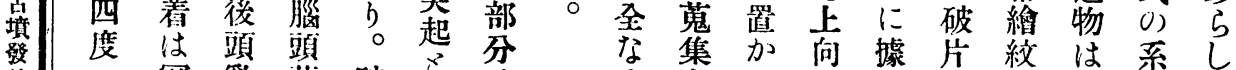

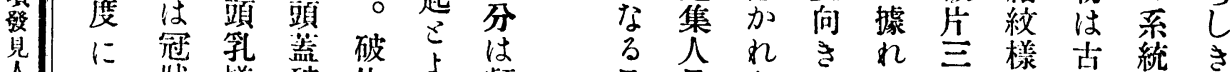

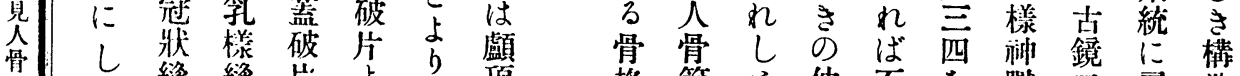

就七 綎 縫 片台

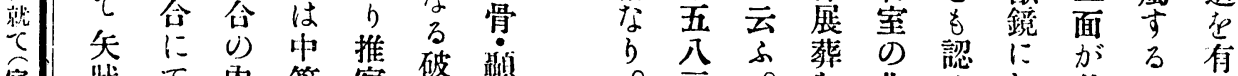

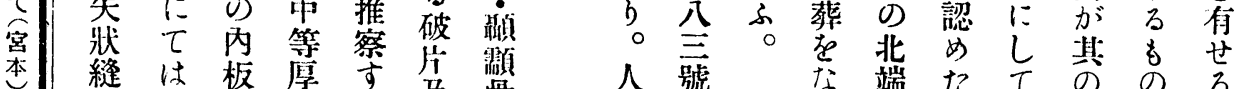

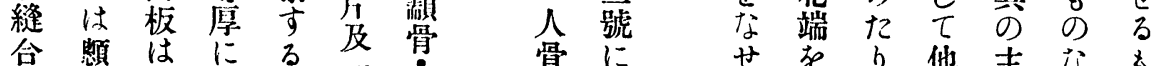

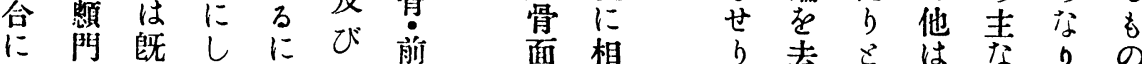

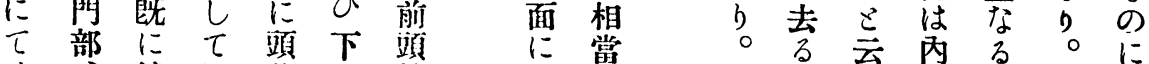

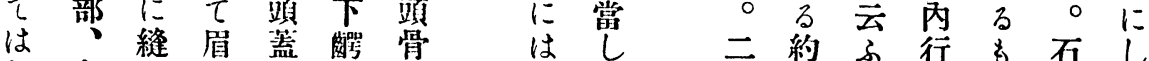

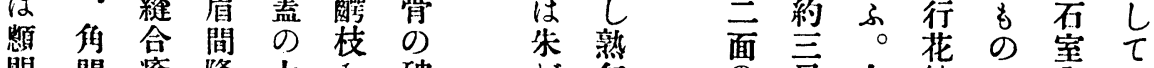

門問瘾隆大歪破年穴人紋に丙石

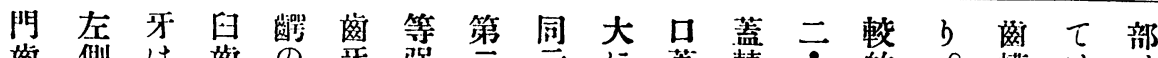

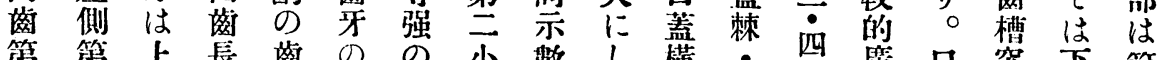

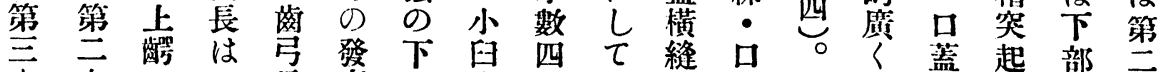

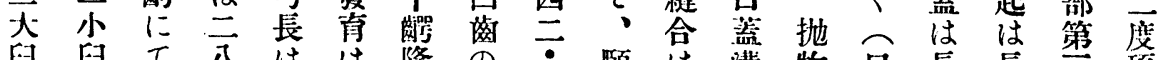

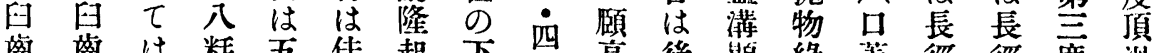

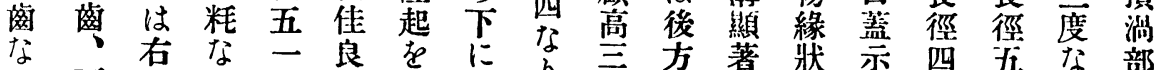

り下側り 粍に有

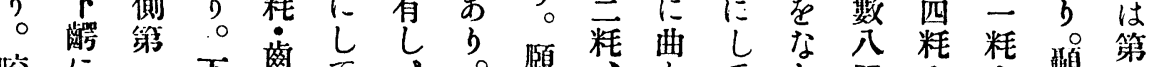

咬に

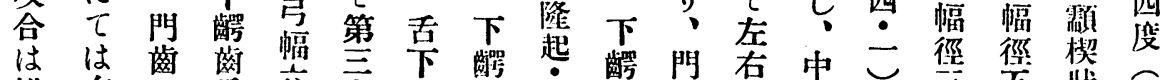

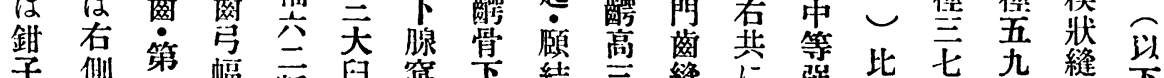

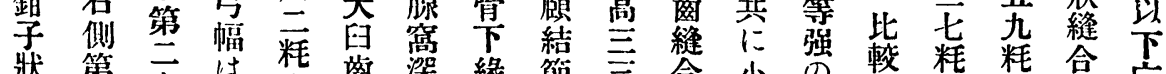

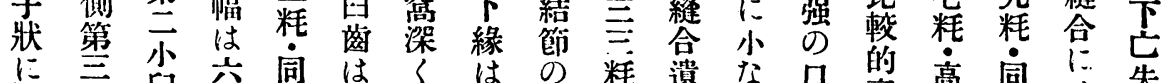

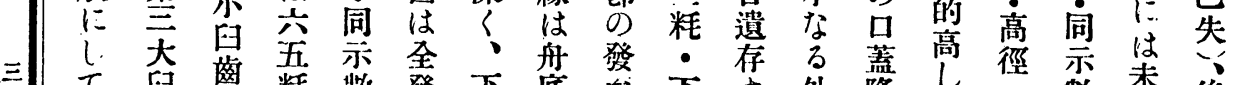

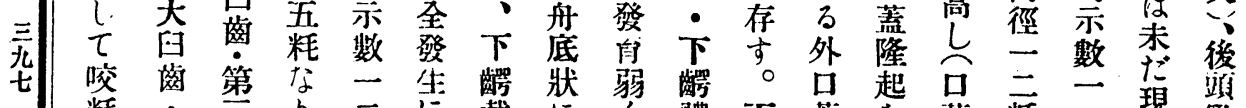

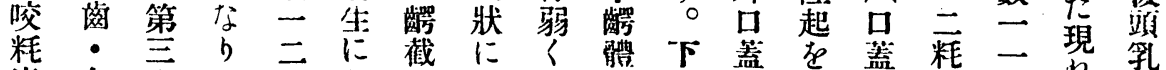

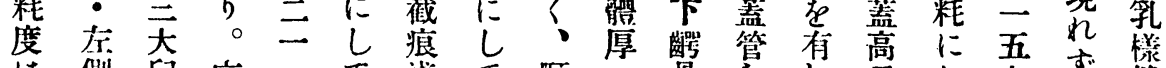

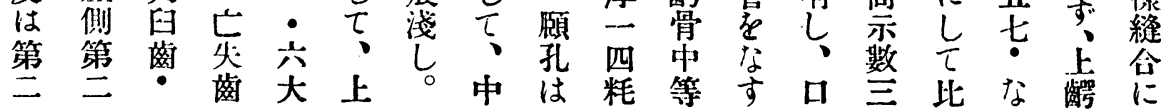




\section{號一十第卷拾四第誌雑學類人}

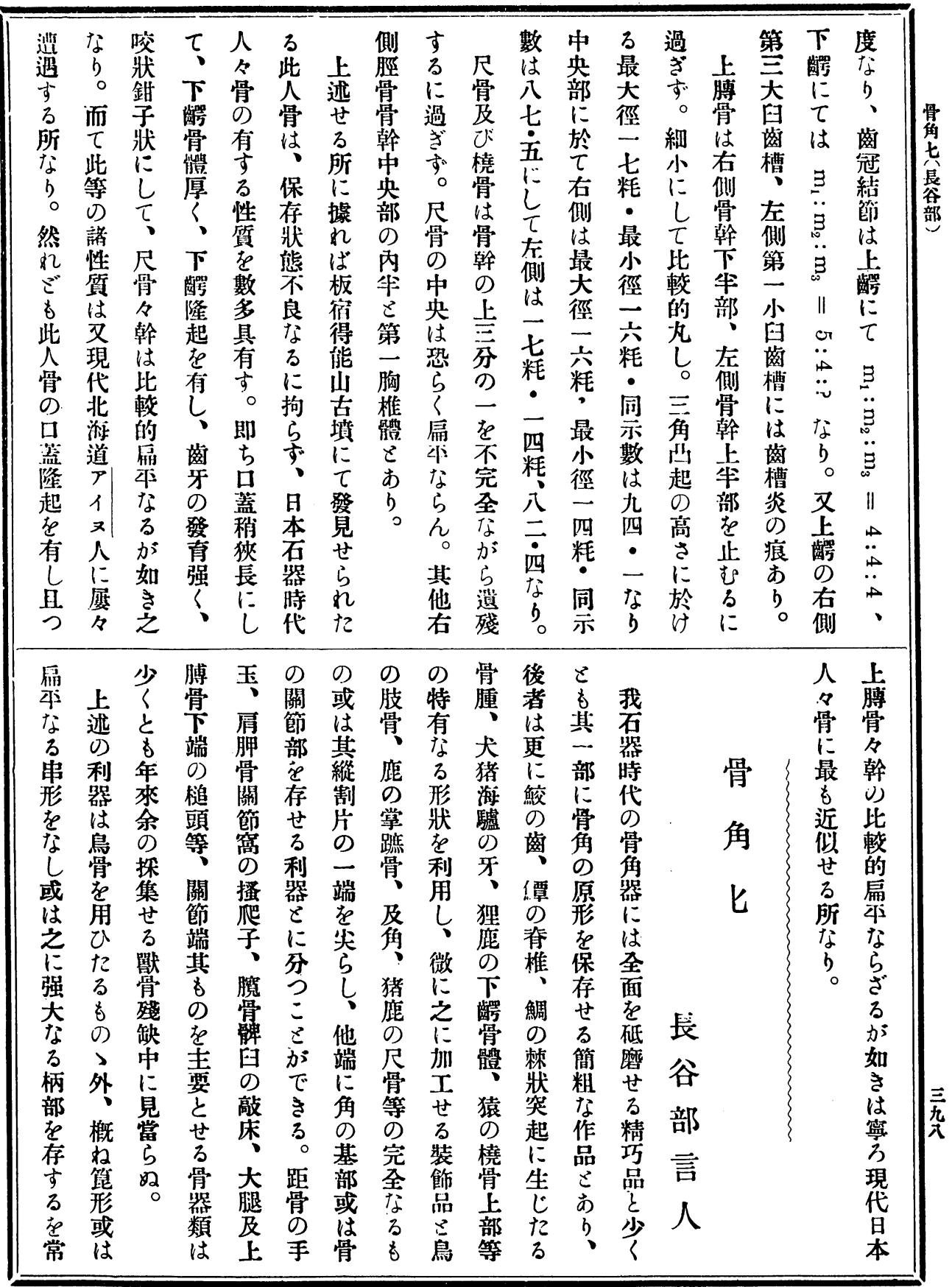

